\title{
Supply Modes of Public Goods in Unexpected Natural Disasters in China
}

\author{
Yang li \\ School of Public Management, Yunnan University of Finance and Economics, China,650221 \\ (Email:yanglikm2000@163.com)
}

\begin{abstract}
In the follow paper, based on the review of relevant journal, analysis of the characteristics and types of public goods supply in unexpected natural disasters. As a basic evidence to prove the demonstrations for collaborative relationship of public goods supply. Moreover, a supply model will be proved based on the public goods supply and main collaborative relations of unexpected natural disasters.
\end{abstract}

Keywords: unexpected natural disaster , public goods , government supply model

\section{Introduction}

With the development of the economy in china, unexpected events are happening more frequently and more seriously. Consequently, unexpected events have brought different kinds of threats to our society. How can we make collaboration between government and society; improve the capabilities of management to respond unexpected events have become very important issues of sustainable development for Chinese government

The most obvious feature of public emergences is that it is very hard to be control, besides, with the development of globalization, information and knowledge, the public issues of unexpected events have become more complicated, and it has limited feasibility of emergency management as a government monopoly functions, therefore, the traditional one-way management which is relied on the Government to respond to public emergencies has necessarily transformed to a brand new model between government and society. On the other hand, globalization and modernity have brought a significant impact to traditional countries, but also enhance the social force and greatly expanded the ability of social self-development and self-realization. Enhancement of social participation makes human a new paradigm of crisis management. Therefore, based on the actual objective, the collaboration between government and society is the crucial factor to resolve the crisis and to jointly promote the development of emergency management.

The management model between government and society reflexes the process that all participants successfully achieve the effective supply of public under the lead of government. there are multiple departments are involved in this goods supply problem and this is an indisputable fact that different kinds of department are making this problem more fragmental. In order to solve this problem, 
we must explore collaborative mechanism to build the supply of public goods. China will have a opportunity to enter a new era of public emergency management, to create a new model which can reflex efforts from government, non-governmental organizations-enterprises social system. Based on the crisis of governance system to focus on the development strategy to build synergy of the whole society emergency governance Network.

The most effective collaboration is use different kinds of advantages in resources, to provide a connected service process to the public, collaboration is a mechanism selection to solve fragmentation of diversified supply of public services. The key problem of the collaboration is to analyse the logic and basis relations behind the collaborative system. Take the goals and interests as the two crucial variables as the starting point to build the analytical framework of the the Emergencies collaborative system.

\section{Unexpected natural disasters, the characteristics and species of the public goods supply}

Because of huge destruction of unexpected natural disasters, it will bring a great impact to social demand and supply structure, some part of the structure can loss its function of normal settings, which causes an serious issue between demand and supply of unexpected natural disaster, and determines the characteristics of public goods of unexpected natural disasters.

\section{1 characteristics of public goods demand natural disasters in unexpected natural} disaster

2.1.1 In unexpected natural disaster, public goods have the characteristics of the time requirements

Unexpected natural disasters have no clear sign about when, where and in which place, and it is very hard to predict how bad the damage could be, Therefore, the urgency of demand for public goods becomes more obvious because of the emergency and uncontrollable of unexpected events. Which requires the supply of public goods become more efficient in the shortest possible time.

In unexpected natural disasters, the demand for public goods has time requirements which includes the requirements of the time period. Because the occurrences of unexpected natural disasters are cyclical, all kinds of disasters have the stage of occurrence, development and reduce. Therefore, we need to come up with different strategies to adjust the supply of public goods.

2.1.2 The spatial characteristic of the demand for public goods in unexpected natural disasters

The spatial characteristic of public goods in the unexpected natural disasters means that the demand and supply of the public goods need to focus on particular locations, resources and information the locations have become the supply center and coherent link .

It is because of the occurrence of unexpected natural disasters have a specific regional, how the local government uses the political resources to play the political advantages to improve the ability to respond the unexpected natural disasters have become 
one of the main content of social management innovation for government.

2.1.3 The demand for public goods with the characteristic of hierarchy in unexpected natural disasters

In different natural disaster, the same product may have different level of public demand, the supply model needs to be created by analysing the type of situation and how serious is the situation.

Unexpected natural disasters are divided into geological disasters, meteorological disasters, biological disasters, marine disasters, and forest and grassland fires. Different types disasters have different causes, effects, propagation and different levels of damage, therefore, the level of public demand will be different in process to respond the unexpected natural disasters.

\subsection{Different types of public goods in unexpected natural disasters}

In unexpected natural disasters, the supply of public goods needs not only consider the needs of people but also the combination between situations and public goods. Therefore, the division of public goods is decided by using dividable lineages, time series is not necessary to be considered as a component for the division of public goods.

Without considering the case of unexpected natural disasters, public goods separability pedigree is divided into: pure public goods, pure private goods and quasi-public goods. Pure public goods can be both non-competitive and non-exclusive; pure private goods can be competitive and exclusive; quasi-public goods take place between pure private goods and pure public goods.

Public goods have its owe sequence in unexpected events: the physical form of public goods, services form the public goods and institutional forms of public goods. Like Before, during and after.

\section{The supply model based on the Collaborative relationship of public goods supply in unexpected natural disasters.}

Under the normal circumstances, the supply of public goods can be divided by private goods, public goods and quasi-public goods. Private goods are supplied by the market, public goods are provided by the policy, quasi-public goods can be not complete non-exclusive , therefore, we can have a variety of modes of supply, private government, groups outside the government, collaboration between private and governmental etc., these modes are likely to become sub-optimal supply options. Under the circumstance of natural disasters, characteristics of public goods supply are as follows:

\subsection{Collaboration between variety of supply sources of public goods in unexpected natural disasters}

It is not enough to divide the supply of public goods just depend on the pedigree in natural disasters. time series of social events needs to be considered as a very important part, the division will be public goods, goods in public service form and goods in institutional forms.

3.1.1 variety of supply sources of public goods in unexpected natural disasters

According to the analysis we mentioned, the whole unexpected event can be divided into three periods of time. And a diagram is created to emphasize these three periods of time. (see Table 1). 


\begin{tabular}{|l|l|l|}
\hline A1 & B1 & C1 \\
\hline A2 & B2 & C2 \\
\hline A3 & B3 & C3 \\
\hline
\end{tabular}

before

after
Table1: types of public goods and variety of supply sources in unexpected natural disasters

The first line in table 1 represents the public goods in institutional forms, the second line represents the public goods in service forms and the third line represents the public goods in physical forms. A column represents the combination of public goods needed by the people in advance stage, the B column represents combination of public goods needed during the process, the $\mathrm{C}$ column represents the combination of public goods needed by people after the process. If we do our analysis only depend on the pedigree, the physical goods of public goods should be supplied by market; institutional forms of public goods should be supplied by the government; service forms of public goods should be provided by both market and government. Part of the A3 and $\mathrm{C} 3$ are supplied by the market, part of the A2 and C2 are supplied multiple sources, part of the $\mathrm{A} 1$ and $\mathrm{Cl}$ are supplied by the government. Zhao Junfeng, The gets emergencies, public goods, the demand and supply, the Chinese line policy management, 2012 (1)

\subsubsection{Collaboration between variety of supply} sources in unexpected natural disasters

There are variety of supply sources in unexpected natural disasters, and they all from different field. It is important to analyse the basis of the collaborative relationship. There are two variables: the goals and the interests. The two variables are the most important components to build the collaborative relationship between different public goods supply sources.

In unexpected natural disasters, public organization sometimes play their own role to against each other, because thy are going for different interests, but they share the same goals. It will need them to communicate and collaborate more frequently, that is how they establish the collaborative systems between different main supply sources.

\section{2 supply mode of public goods in unexpected natural disasters}

Based on the analysis about the supply mode in unexpected disasters just mentioned, government will be the lead in the supply mode and another organizations and media will be the part of the collaboration system.

During the process of the events, normal channels can not complete demand of all people, therefore, some extra powers need to be involved to complete the people's need. During the process of the disasters, the characteristic of items will change with the time series. The goods will be private before the events, it will become the public goods during the process, and it will become to private goods after the events. One particularly good example is the food.

Therefore, based on the variability of unexpected natural disaster and the diversity of the public demand, it has to have the government as the leader, and we also need the efforts from social organizations, media, companies and citizens. It is important to create a strong supply model with variety of supply sources in order to respond the unexpected event as efficient as we can. 


\section{Conclusion}

How to deal with unexpected natural disasters has become a significant issue for Chinese government, and supply mode is the most important issue for the management of unexpected natural disasters. First, try the best to consummate the supply system in order to efficiently respond the unexpected event, make the procedure of goods supply in a very good order. Second, complete the communication system between different supply sources, in order to respond the natural disasters at the first place. All participants need to put their efforts in a more efficient way by under the lead of the government.

\section{References}

[1]Jin Taijun, Zhao Junfeng. On the Demand and Supply of Public Goods in Emergencies[j]. Chinese Public Administration, 2012,1(1):101 105

[2]Zhou Xiaoli. On the Governance of the Disaster Public Crisis[M]. Social Science Academic Press, 2008 (In Chinese)

[3]Wang Jinjun, To Build Coordination Mechanisms of Public Services: A Defining Framework[j]. Chinese Public Administration, 2012,1:18 22 